\title{
MUSEUM ALAT MUSIK TRADISIONAL DAN GEDUNG OPERA DI SURAKARTA BERPENDEKATAN ARSITEKTUR METAFORA
}

\author{
Dennis Kresnatama Basta \\ Program Studi Arsitektur, Fakultas Teknik, Universitas Tunas Pembangunan Surakarta \\ dendenisss006@gmail.com \\ Danarti Karsono \\ Dosen Program Study Arsitektur, Fakultas Teknik, Universitas Tunas Pembangunan \\ Email: danartikarsono@yahoo.com \\ Ismadi \\ Dosen Program Study Arsitektur, Fakultas Teknik, Universitas Tunas Pembangunan \\ Email: ismadi.ir@gmail.com
}

\begin{abstract}
Abstrak
Perkembangan pariwisata kota Surakarta semakin meningkat tiap tahunnya. Selain itu sektor industri, perdagangan dan jasa pembangunannya juga semakin maju, hal ini juga didukung oleh faktor letak geografis. Peluang dan potensi yang dimiliki Kota Surakarta sangat besar dalam peningkatan dan pendapatan di sektor parawisata. Konsep perencanaan Museum Alat Musik Tradisional dan Gedung Opera di Kota Surakata, mengacu pada pariwisata edukasi tentang budaya indonesia sebagai penunjung program pemerintah serta mendukung pariwisata-pariwisata yang ada di Jawa Tengah. Dengan merencanakan Museum Alat Musik Tradisional dan Gedung Opera di Surakarta ini merupakan upaya kongkrit, wujud konsekuensi sebagai kota budaya. Serta dapat mendukung aspek pengetahuan alat musik tradisional, ekonomi dan pariwisata. Diharapkan dengan terwujudnya Museum Alat Musik Tradisional dan Gedung Opera di kota Surakarta dapat menjadikan wadah untuk koleksi alat musik tradisional, pementasan alat musik tradisional dan menambah wawasan tentang alat musik tradisional Indonesia bagi masyarakat. Museum Alat Musik Tradisional dan Gedung Opera di Surakarta diharapkan mampu menjadi tujuan wisata seni budaya bangsa, memiliki fungsi pelestarian sekaligus pendidikan bagi generasi muda terhadap alat musik tradisional dan sebagai daya Tarik masyarakat agar selalu mencintai alat musik tradisional.
\end{abstract}

Kata kunci: Museum Alat Musik Tradisional dan Gedung Opera

\begin{abstract}
The development of tourism city Surakarta also improves every year. Inaddition the industrial sector, trade and services the development also more advanced, this too is supported by a factor of geographical location. Opportunities and potentials city Surakarta very large in increase and income in parawisata sector. The concept of planning Museum Musical Instrument and Opera House Surakata, referring to the need for accommodation services as government programs and to support pariwisata that is in central java. By planning the Museum of Traditional Musical Instruments and the Opera House in Surakarta this is a concrete effort, a manifestation of the consequences as a cultural city. And can support aspects of knowledge of traditional musical instruments, economics and tourism. It is hoped that the realization of the Museum of Traditional Musical Instruments and the Opera House in the city of Surakarta can make a container for a collection of traditional musical instruments, staging traditional musical instruments and adding insight into traditional Indonesian
\end{abstract}


musical instruments for the community. The Museum of Traditional Musical Instruments and the Opera House in Surakarta is expected to be able to become an art and culture destination of the nation, has a preservation function as well as education for the younger generation of traditional musical instruments and as an attraction for people to always love traditional musical instruments.0

Keywords: Tradisional Musical Instrument Museum and Opera Building

\section{PENDAHULUAN}

Indonesia sebagai bangsa yang besar mempunyai ciri dan adat kebiasaan yang disebut dengan kebudayaan, yang merupakan hasil karya dan pengetahuan yang dimiliki manusia. Kesenian merupakan salah satu unsur yang memberikan sifat khusus yang membedakan bangsa Indonesia dengan bangsa lainnya dan Alat musik tradisional sangatlah beragam yang membedakan suatu daerah dengan daerah lainnya di Indonesia. Hal ini dapat dilihat dari ragam alat musik tradisional yang ada di Indonesia dan Kesenian merupakan salah satu unsur yang memberikan sifat khusus Hal ini dapat dilihat dari ragam dan besarnya frekuensi pertunjukan musik digelar tiap tahunnya.

Pengaruh globalisasi dunia semakin besar, arus informasi semakin mudah dan bebas didapat dan perkembangan ilmu pengetahuan dan teknologi berjalan dengan cepat dan semakin canggih. Hal ini secara tidak langsung berpengaruh pada perkembangan kebudayaan di Indonesia, sehingga kebudayaan yang terjadi tidak luput dari pengaruh kebudayaan asing, membuat kurangnya daya tari dan pengetahuan tentang budaya alat musik tradisional di Indonesia.

Kota Surakarta, merupakan salah satu kota yang masih sangat lekat dengan kebudayaan Jawa mempunyai potensi yang cukup besar dalam bidang budaya, pariwisata dan perdagangan. Latar belakangnya berupa tempattempat budya seperti taman sriwedari, keratin Surakarta taman budaya Surakarta dan museum radya pustaka yang membuat nilai-nilai budaya dan tradisi mengakar kuat dalam kehidupan masyarakat Surakarta. Semakin meningkatnya apresiasi seni dan budaya telah menunjukkan bahwa seni dan budaya merupakan hal yang tidak dapat dipisahkan dari kehidupan manusia.

Sedangkan pengertian museum menurut Drs. P. Robert Silalahi, museum adalah sebuah lembaga yang bersifat tetap, tidak mencari keuntungan, melayani rakyat dan perkembangannya, terbuka untuk umum, yang memperoleh, merawat, menghubungkan dan memamerkan, untuk tujuan-tujuan studi, Pendidikan dan kesenangan, barang-barang pembuktian manusia dan lingkungannya (Drs. P. Robert Silalahi, Pedoman Museum). Museum yang terdapat di Karesidenan Surakarta yaitu Museum Keraton Solo, Museum Radyapustaka, Museum Batik Danar Hadi, Museum Pers Nasional, Museum Lukis Dullah, Museum Pura Mangkunegaran dan Museum Keris. Museum juga digunakan sebagai sumber pendidikan di kota Surakarta seperti yang tertulis di Undang-undang Nomor 11 tahun 2010 tentang Cagar Budaya. Seperti yang tertuang dalam pasal 2 yang berbunyi: "Museum mempunyai tugas pengkajian, pendidikan, dan kesenangan".

Dengan merencanakan Museum Alat Musik Tradisional dan Gedung Opera di Surakarta ini merupakan upaya kongkrit, wujud konsekuensi sebagai kota budaya. Serta dapat mendukung aspek pengetahuan alat musik tradisional, ekonomi dan pariwisata. 
Diharapkan dengan terwujudnya Museum Alat Musik Tradisional dan Gedung Opera di kota Surakarta dapat menjadikan wadah untuk koleksi alat musik tradisional, pementasan alat musik tradisional dan menambah wawasan tentang alat musik tradisional Indonesia bagi masyarakat. Museum Alat Musik Tradisional dan Gedung Opera di Surakarta diharapkan mampu menjadi tujuan wisata seni budaya bangsa, memiliki fungsi pelestarian sekaligus pendidikan bagi generasi muda terhadap alat musik tradisional dan sebagai daya Tarik masyarakat agar selalu mencintai alat musik tradisional.

Perencanaan Museum Alat Musik Tradisional dan Gedung Opera di Surakarta sebagai pusat pelestarian alat musik tradisional merupakan daya tarik terhadap alat musik tradisional, pusat rekreasi budaya, edukasi tentang alat musik tradisional dan macam - macam alat musik tradisional di Jawa, di kemas dalam bangunan museum dan gedung opera dengan desain arsitektur Metafora di Surakarta sebagai kosep bentuk salah satu alat musik tradisional di Indonesia.

\section{METODE PENELITIAN}

A. Permasalahan

Bagaimana Merencanakan dan Merancang bangunan Museum Alat Musik Tradisional dan Gedung Opera di Surakarta yang memiliki daya tarik masyarakat terhadap musik tradisional

\section{B. Metode Penelitian}

1) Pengumpulan data, yaitu pengumpulan data sekunder untuk bekal survey lapangan guna menghasilkan data primer dan eksplorasi data sekunder melalui literatur dan wawancara.

2) Kompilasi data, yaitu menyusun, memilah-milah dan mengklasifikasikan data, kedalam bagian-bagian yang relevan.
3) Analisis, yaitu pengkajian data dan informasi yang didapat dengan pencarian data yang akan digunakan dalam penyusunan konsep perencanaan dan perancangan.

4) Sintesis, yaitu menggabungkan hasil analisis data ke dalam konsep perencanaan dan perancangan Tugas Akhir yang akan dilanjutkan dalam tahap studio Tugas Akhir.

\section{Landasan Teori}

1) Pengertian Museum

Museum adalah institusi permanen, nirlaba, melayani kebutuhan publik, dengan sifat terbuka, dengan cara melakukan usaha pengoleksian, mengkonservasi, meriset, mengomunikasikan, dan memamerkan benda nyata kepada masyarakat untuk kebutuhan studi, pendidikan, dan kesenangan.

2) Pengertian Gedung Opera

Suatu kegiatan mempertunjukan orkestra karya seni kepada orang lain (masyarakat umum) agar mendapat tanggapan dan penilaian gedung opera mempunyai karakter adanya sebuah pemisahan ruang yang jelas secara arsitektur antara ruang penonton dan panggung melalui musik orkestra dan banyaknya tempat duduk (1000 sampai hampir 4000 tempat duduk) dan sistem yang sesuai dengan tempat duduk tidak terikat (lepas) atau balkon, penting untuk jumlah penonton yang banyak.

3) Pengertian Alat Musik Tradisional

Alat musik tradisional adalah alat-alat musik yang berkembang secara turuntemurun pada suatu daerah yang digunakan untuk mengiringi lagu-lagu daerah asal berkembangnya alat musik tersebut. Indonesia adalah negara yang kaya akan seni budaya, begitu pula dengan alat musik tradisional.

4) Pengertian Arsitektur Metafora

Metafora merupakan bagian dari gaya Bahasa yang di gunakan menjelaskan sesuatu melalui persamaan dan perbandingan. Pengertian Metafora 
dalam Arsitektur adalah kiasan atau ungkapan bentuk yang di wujudkan dalam bangunan dengan harapan akan menimbulkan tanggapan dari orang yang menikmati atau memakai karyanya.

\section{LANDASAN TEORI}

1. Museum Alat Musik Tradisional dari definisi museum rumusan ICOM, sutaarga (1989: 28) mengemukakan sembilan fungsi museum sebagai berikut:

a) Pengumpulan dan pengamanan warisan alam dan budaya.

b) Dokumentasi dan penelitian ilmiah.

c) Konservarsi dan reservasi.

d) Penyebaran dan pemerataan ilmu untuk umum.

e) Pengenalan dan penghayatan kesenian.

f) Pengenalan kebudayaan antar daerah dan antar bangsa.

g) Visualisasi warisan alam dan budaya.

h) Cermin pertumbuhan peradaban umat manusia.

i) Pembangkit rasa bertakwa dan bersyukur kepada Tuhan Yang Maha Esa.

2. Berdasarkan tingkatan koleksinya, jenis museum dibagi menjadi 3 (tiga), diantaranya (menurut nternational Council of Museum (ICOM) pada tahun 1974 di Denmark) yaitu:

a.Museum Nasional

Museum Nasional adalah jenis museum yang memiliki tingkatan koleksi sesuai dengan kelas nasional atau dalam taraf nasional. Museum ini umumnya berisi berbagai benda yang berisi dari berbagai daerah di suatu negara.

b.Museum Regional

Museum regional adalah jenis museum yang memiliki tingkatan koleksi terbatas dan hanya dalam lingkup daerah regional. Museum ini umumnya koleksinya berasal dari daerah regional tempat museum tersebut berdiri.

c. Museum Lokal
Museum lokal adalah jenis museum yang memiliki tingkatan koleksi dalam taraf daerah saja. Benda yang dikoleksi dalam museum tersebut hanya terbatas pada warisan dan budaya yang ada pada daerah itu saja.

3. Teater Berdasarkan Kapasitas

Jenis teater juga dapat diklasifikasikan menurut kapasitas penonton yang ditampungnya (Ham, 1987):

a. Sangat Besar Gedung Pertunjukan yang memiliki 1500 kursi penonton atau lebih.

b. Besar

Gedung Pertunjukan yang memiliki 900 - 1500 kursi penonton.

c. Sedang

Gedung Pertunjukan yang memiliki 500-900 kursi penonton.

d. Kecil

Gedung Pertunjukan yang memiliki kurang dari 500 kursi penonton.

Gedung Opera di Surakarta memiliki klasifikasi berdasarkan kapasitas penonton yang di tampung. Klasifikasi Sedang Gedung yang memiliki 500900 kursi penonton.

\section{PEMBAHASAN}

\section{A. Rekapitulasi Data Perhitungan}

Besaran Ruang Museum Alat Musik Tradisional

\begin{tabular}{|c|c|c|}
\hline No & Nama Fasilitas & Besaran Total $\left(\mathrm{m}^{2)}\right.$ \\
\hline 1 & Kelompok Penerimaan Museum & $647,48 \mathrm{~m} 2$ \\
\hline 2 & Kelompok Pengelola Museum & $977,8 \mathrm{~m} 2$ \\
\hline 3 & Kelompok Koleksi Museum & $1040,2 \mathrm{~m} 2$ \\
\hline 4 & Ruang Pameran & 1004 \\
\hline 5 & Kelompok Keamanan & $362,25 \mathrm{~m} 2$ \\
\hline 6 & Kelompok service & $287,5 \mathrm{~m} 2$ \\
\hline 7 & Kelompok Parkir & $4.305,2 \mathrm{~m} 2$ \\
\hline 8 & Luas Total & $8.846,6 \mathrm{~m}^{2}$ \\
\hline
\end{tabular}

Besaran Ruang Gedung Opera 


\begin{tabular}{|c|c|c|}
\hline No & Nama Fasilitas & Besaran Total $\left(\mathrm{m}^{2)}\right.$ \\
\hline 1 & Kelompok Penerimaan & $647,45 \mathrm{~m} 2$ \\
\hline 2 & Kelompok Pengelola & $834 \mathrm{~m}^{2}$ \\
\hline 3 & Kelompok Pagelaran & $2.029,75 \mathrm{~m}^{2}$ \\
\hline 4 & Kelompok Keamanan & $362,25 \mathrm{~m} 2$ \\
\hline 5 & Kelompok Servis & $287,5 \mathrm{~m}^{2}$ \\
\hline 6 & Kelompok Parkir Luar Bangunan & $4.305,2 \mathrm{~m}^{2}$ \\
\hline 9 & Luas Total & $\mathbf{9 . 4 6 6 ~ \mathbf { m } ^ { 2 }}$ \\
\hline
\end{tabular}

Berdasarkan RUTRK Kota Surakarta tentang peraturan pembangunan maka jumlah lantai dapat diketahui sebagai berikut:

Luas Site: 26,406 $\mathrm{m}^{2}$

Kebutuhan Ruang Ketinggian Museum = $8.846,6 \mathrm{~m}^{2}$

Ketinggian Gedung Opera $=9.466 \mathrm{~m}^{2}$

Ketinggian Penunjang Cafe $=1.900 \mathrm{~m}^{2}$

KDB : $40 \%$ dari total luas tapak : $40 \%$ x $26.406 \mathrm{~m}^{2}$

\section{$\mathbf{1 0 . 5 6 2 , 4 ~ \mathbf { ~ m 2 }}$}

KDH : $60 \%$ Dari Luas Tapak : $60 \% \times 26.406 \mathrm{~m}^{2}$

\section{: $15.844 \mathrm{~m} 2$}

a. Ketinggian Museum = total jumlah ruang Museum / jumlah ruang per lantai. (45\% dari $\mathrm{KDB})$

$$
=8.846,6 / 4.224,96
$$

= 2.1 lantai dibulatkan menjadi 3 lantai

b. Ketinggian Gedung Opera $=$ total jumlah ruang Gedung Opera/ jumlah ruang per lantai. (45\% dari KDB)

$$
\begin{aligned}
= & 9.466 / 4.224,96 \\
= & \mathbf{2 . 2} \text { lantai dib } \\
& \text { lantai }
\end{aligned}
$$$$
\text { = } 2.2 \text { lantai dibulatkan menjadi } 2
$$

c. Ketinggian Penunjang $=$ jumlah ruang Penujang Cafe / jumlah ruang per lantai. $(10 \%$ dari $\mathrm{KDB})$

$=1.900 / 1.056,24$

= 1.9 dibulatkan menjadi 2 lantai.
1) Lokasi tapak strategis.

2) Aksebelitas ke tapak mudah.

3) Lokasi memiliki daya tarik yang tinggi.

4) Aksebelitas dengan fasilitas pendukung baik.

Lokasi tapak berada di daerah Sriwedari, JL.Bhayangkara.

1) Lebar jalan di sekitar tapak $8 \mathrm{~m}^{2}$ merupakan 2 jalur.

2) Jarak dari jalan utama menuju ke lokasi $200 \mathrm{~m}$
3) Topogr
Gambar 1 Lokasi
4) Luas Lahan : $26.406,00 \mathrm{~m}^{2}$
5) $\mathrm{KDB}: 40 \%-60 \%$

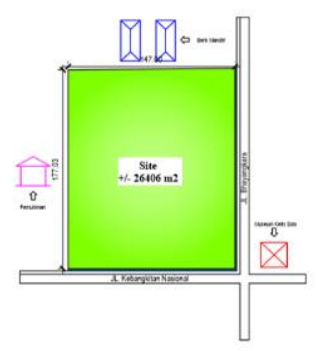

Gambar 2 Tapak

\section{Pencapaian}

Alternatif pencapaian secara administrasi

Kota Surakarta berbatasan dengan:

Sebelah utara: Kabupaten Dati II Karanganyar, Kabupaten Dati II Boyolali Sebelah selatan: Kabupaten Dati II Sukoharjo

Sebelah timu: Kabupaten Dati II Karanganyar, Kabupaten Dati II Sukoharjo

Sebalah barat: Kabupaten Dati II Sukoharjo, Kabupaten Dati II Boyolali.

Hasil $=$ Alternatif 2 di jadikan Main Enterance (ME)

Alternatif 1 di jadikanMain Side Enterance (SE)

$$
\text { Gambar } 3 \text { Pencapaian }
$$

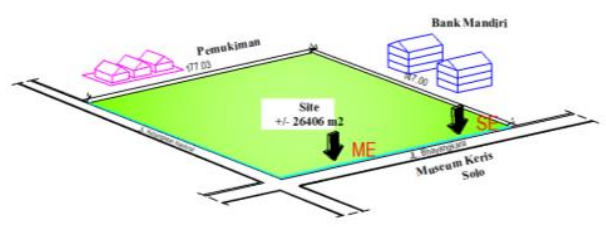




\section{Orientasi}

Dasar pertimbangan analisis Orientasi bangunan:

Menonjolkan pengenalan bangunan.

Mengarahkan pengunjung menuju enterance bangunan secara efektif (cepat, mudah, lancar).

Orientasi bangunan yang strategis untuk memudahkan pengarah atau petunjuk pada bangunan.

Kesesuaian dengan pencapaian bangunan.

E. Titik Tangkap

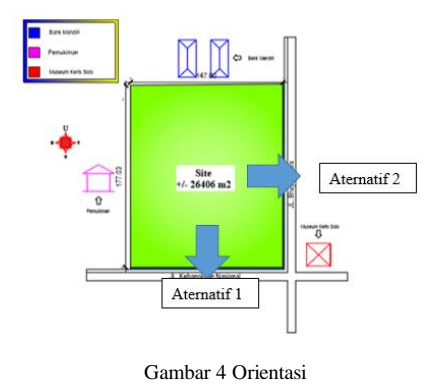

Dasar pertimbangan analisis titik tangkap:

Titik tangkap terbesar diambil dari intensitas pemakai jalan terbesar dan mulai batas pandang terjauh dari tapak

Sudut pandang mobil 30 derajat, pengendara motor 45 derajat, dan sudut pandang manusia 180 derajat

Area titik tangkap terbesar dimanfaatkan untuk penempatan point of interst bangunan dan pengenalan terhadap fungsi bangunan

\section{F. Kebisingan}

Dasar pertimbangan analisis kebisingan:

Letak dan arah sumber kebisingan.

Perbandingan antara tingkat kebisingan dan ketenangan.

Arus lalu lintas yang ada.

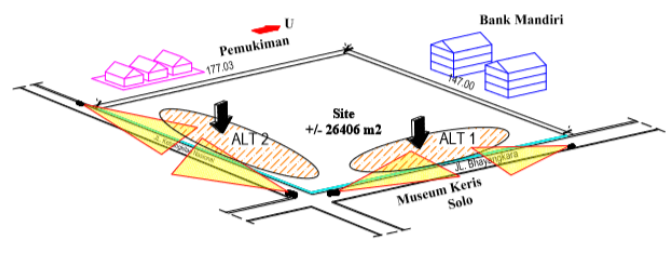

Gambar 6 Kebisingan

G. Matahari

Dasar pertimbangan analisis orientasi terhadap matahari:

Pemanfaatkan sinar matahari yang tidak langsung / sinar pantul agar tidak menyilaukan

Menghindari sinar matahari yang berlebihan

Memanfaatkan sinar matahari yang cukup untuk bangunan

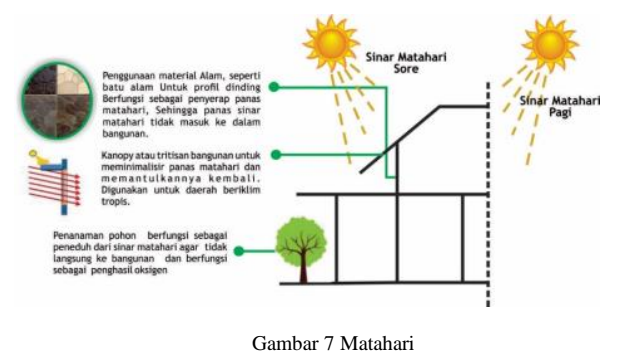

H. Zonning

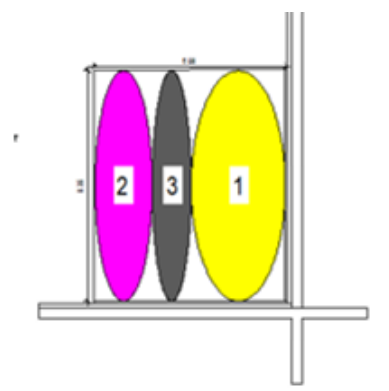

Keterangan:

1. Zona Publik

2. Zona Semi

Publik

3. Zona Privat

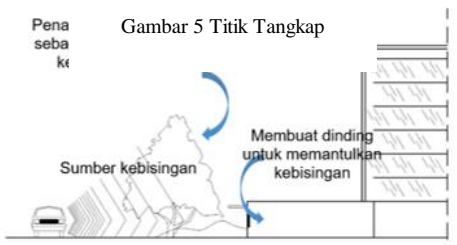

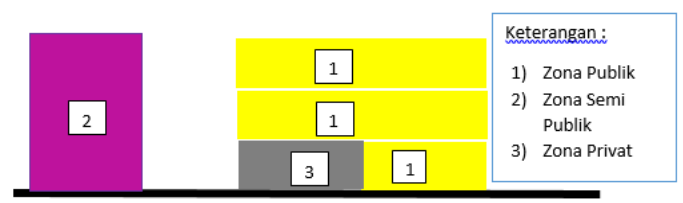

Gambar 9 Zonning Vertikal

\section{Penampilan Bangunan}




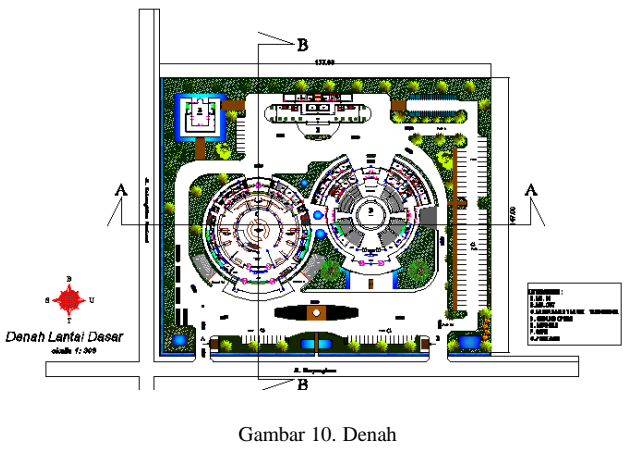

Konsep Penampilan Bangunan

Konsep penampilan bangunan adalah untuk mewujudkan penampilan bangunan Museum Alat Musik Tradisional dan Gedung Opera yang memiliki daya Tarik masyarakat yang tinggi.
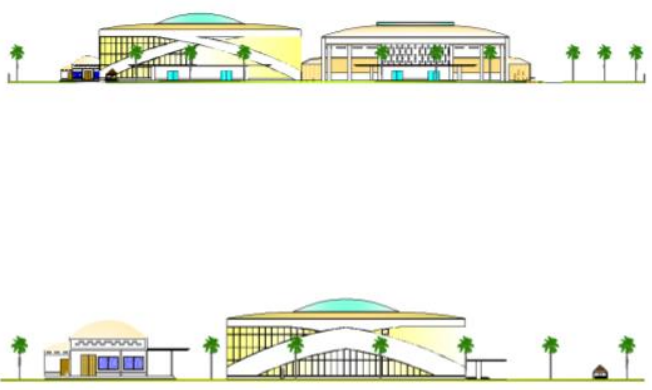

Gambar 11. Tampak Timur dan Selatan

Memiliki bentuk bangunan yang mencerminkan suatu Museum Alat Musik Tradisional dan Gedung Opera tampa harus masuk kedalam bangunan.

Mesesuaian dengan penekanan permasalahan bangunan yang memiliki daya Tarik yang tinggi.

Membentuk bangunan yang berbeda dari bangunan di sekitar Museum Alat Musik Tradisional dan Gedung Opera.

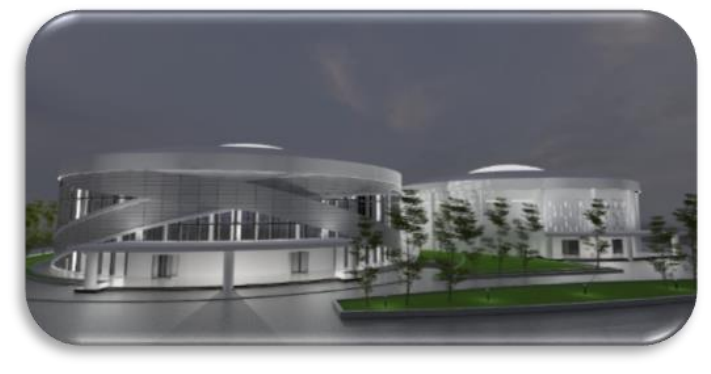

Gambar 12 Perspektif Museum dan Gedung opera
Berdasarkan pendekatan konsep penampilan bangunan penggunaan material kayu, logam dank kaca sesuai untuk mendukung bentuk metafora dari Alat Musik Tradisional Gong dan Seruling. Fasade bangunan memiliki filosofi yaitu seperti alat musik tradisional Indonesia Gong dan Seruling dimana fungsi utama dari Museum Alat Musik Tradisional dan Gedung Opera adalah memberikan wawasan dan hiburan tentang alat music tradisional Indonesia.

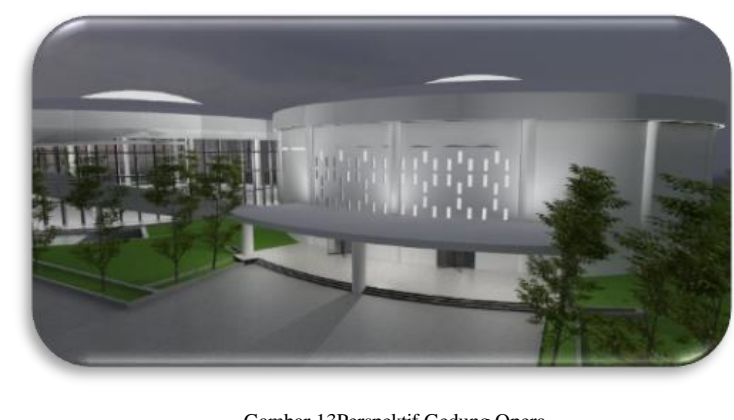

Gambar 13Perspektif Gedung Opera

\section{KESIMPULAN/RINGKASAN}

Museum Alat Musik Tradisional dan Gedung Opera memiliki konsep salah satu alat musik tradisional Indonesia alat musik tradisional gong yang di jadikan sebagai konsep bentu dasar bangunan untuk mendapatkan daya tarik yang tinggi terhadap musik tradisional Indonesia

Memiliki bentuk bangunan yang mencerminkan suatu Museum Alat Musik Tradisional dan Gedung Opera tampa harus masuk kedalam bangunan.

Mesesuaian dengan penekanan permasalahan bangunan yang memiliki daya Tarik yang tinggi. Membentuk bangunan yang berbeda dari bangunan di sekitar Museum Alat Musik Tradisional dan Gedung Opera.

\section{UCAPAN TERIMA KASIH}

Penulis mengucapkan terima kasih kepada:

1. Ir. Eny Krisnawati, M.Si., selaku Dekan FT UTP.

2. A.Bamban Yuuwono, ST., MT. Selaku Ketua 
Prodi Arsitektur FT.Teknik

3. Ir. Danarti Karsono, MT selaku Dosen Pembimbing Utama.

4. Ir. Ismadi, MT., selaku Dosen Pembimbing.

5. Orang tua dan keluarga yang memberikan dukungan baik secara moral maupun materi kepada penulis.

6. Elizabeth Andriani Anggun.

7. Semua teman-teman Arsitektur angkatan 2015.

8. Semua pihak yang tidak dapat disebutkan satu per satu, yang telah ikut membantu secara langsung maupun tidak langsung.

\section{DAFTAR PUSTAKA}

Undang-undang Nomor 11, Pasal 2 tahun 2010 tentang Cagar Budaya

Badan Pusat Statistik Surakarta, 2016.

Kamus Besar Bahasa Indonesia

Supriyo, dkk. 2008. Pedalangan : Jilid 1.

Direktorat Pembinaan Sekolah Menengah

Kejuruan.

"Arsitektur Tradisional Daerah Istimewa

Yogyakarta"

Departemen Pendidikan Dan Kebudayaan RI, Jakarta, 1998.

Neufert, Ernest, Jilid 2, Data Arsitek, Jakarta :

Erlangga.

ICOM. 2007. Kode Etik Icom Untuk

Permusueuman. Jakarta: Direktorat Jenderal

Permuseuman

Direktorat Museum. 2009 . Ayo Kita Mengenal

Museum. Jakarta: Departemen Kebudayaan dan

Pariwisata

Susilo dkk, 1993: 27

Susilo dkk, 1993: 19

Suutarga, Amir 1989. Pedoman

Penyelenggaraan dan Pengelolaan Museum.
Jakarta: Proyek Pembinaan Permuseuman

Jakarta Direktorat Jenderal Departemen

Pendidikan dan Kebudayaan.

Egan (Winaya, 2010)

Sagio dan Ir. Samsugi. 1991. Wayang kulit Gagrag Yogyakarta, Jakarta: CV Haji Masagung Sri Mulyono. 1983. Simbolisme dan Mistikisme dalam Wayang, Jakarta: CV Haji Masagung. 